\title{
Comportamento fenológico de cultivares de Vitis rotundifolia em Pinhais - PR ${ }^{1}$
}

\section{Phenological behaviour of Vitis rotundifolia cultivars in Pinhais - PR}

\author{
Sergio Denega ${ }^{2}$; Luiz Antonio Biasi ${ }^{3 *}$; Flávio Zanette ${ }^{3}$
}

\section{Resumo}

O objetivo foi caracterizar o ciclo fenológico de nove cultivares de Vitis rotundifolia avaliadas na safra de 2004/2005. As cultivares estudadas foram as seguintes: Bontiful, Creek, Dixie, Magnolia, Magoon, Noble, Regale, Roanoke e Topsail. O trabalho foi realizado em um pomar do Setor de Fruticultura da Estação Experimental do Canguiri da Universidade Federal do Paraná, em Pinhais-PR, sendo que as cultivares foram plantadas em julho de 1999. A fenologia foi observada em duas plantas adultas de cada cultivar. Os estádios fenológicos observados foram os seguintes: 1) Gema dormente; 2) Gema inchada; 3) Gema algodão; 4) Ponta verde; 5) $1^{\text {a }}$ folha separada; 6) 2 a 3 folhas separadas; 7 ) 5 a 6 folhas separadas; 8) Inflorescência desenvolvida; 9) Botões florais separados; 10) 50\% das flores abertas; 11) Frutificação; 12) Grãos "chumbinho"; 13) Grãos "ervilha"; 14) Meia-baga; 15) Tamanho final; 16) Mudança de cor; 17) Maturação plena; 18) Término da colheita. Constatou-se um ciclo bastante longo das cultivares da espécie estudada, quando comparada a outras espécies, como Vitis vinifera e Vitis labrusca. As avaliações realizadas permitiram concluir que: a) não há diferença do ciclo entre as cultivares de cores branca e tinta; b) as cultivares apresentam grande variação na duração da fase de gema algodão até a inflorescência desenvolvida, variando de 25 dias ('Regale') até 81 dias ('Creek'); c) o período entre o aparecimento da inflorescência e a colheita foi mais longo na cultivar Regale (203 dias) e mais curto na cultivar Creek (136 dias). As cultivares desta espécie apresentam ainda desuniformidade de maturação e elevada degrana.

Palavras-chave: Fenologia. Videira. Muscadínea. Fruticultura.

\begin{abstract}
The aim of this work was to characterize the phenological cycle of nine Vitis rotundifolia cultivars during the 2004/2005 season. The cultivars were Bontiful, Creek, Dixie, Magnolia, Magoon, Noble, Regale, Roanoke e Topsail. The experiment was performed on an orchard implanted in 1999 at the Canguiri Experimental Station of the Federal University of Paraná in Pinhais-PR. The phenology of two adult plants of each cultivar was monitored. The recorded phenological stages were: 1) Dormant bud; 2) Swollen bud; 3) Wool bud; 4) Green tip; 5) Bud burst (first leaf appearance); 6) Two to three leaves unfolded; 7) Five to six leaves unfolded; 8) Fully developed inflorescence; 9) Trace bloom (flowerhoods detached); 10) Full flowering (50\% of the flowerhoods fallen); 11) Fruit set; 12) Groat-sized berries; 13) Pea-sized berries; 14) $50 \%$ filled berries (beginning to touch berries); 15) Final size; 16) Color change; 17) Berries ripe for harvest; and 18) End of harvesting. A very long phenological cycle was observed when compared to species such as Vitis vinifera and Vitis labrusca. These evaluations allowed
\end{abstract}

1 Parte da Tese de Doutorado do primeiro autor apresentada ao Programa de Pós-Graduação em Agronomia - Produção Vegetal da Universidade Federal do Paraná. Curitiba - PR.

2 Eng. Agr., Dr. Departamento de Agronomia, UNICENTRO. Rua Simeão Camargo Varela de Sá, n 03. Bairro Cascavel, CEP 85.065-090. Guarapuava - PR. E-mail: sdenega@unicentro.br.

3 Eng. Agr., Dr. Professor. Departamento de Fitotecnia e Fitossanitarismo. Universidade Federal do Paraná. Caixa Postal 19061. CEP 81.531-990. Curitiba - PR. Bolsista de Produtividade em Pesquisa do CNPq. E-mail: biasi@ufpr.br.

* Autor para correspondência 
us to conclude that: a) there is no difference in the phenological cycle periods between bronze and dark skinned cultivars; b) cultivars presented desuniform wool bud to full flowering cycle, ranging from 25 days ('Regale') to 81 days ('Creek'); c) the cultivar Regale presented the longest cycle (203 days) from full flowering to harvest and the cultivar Creek the shortest (136 days). The evaluated cultivars additionally presented desuniform ripening and a tendency to drop berries.

Key words: Phenology, vines, muscadines, fruit production

Fenologia é o ramo da ecologia que estuda os fenômenos periódicos dos seres vivos e suas relações com as condições do ambiente. O estudo da fenologia na viticultura tem como objetivo principal caracterizar a duração das fases do desenvolvimento da videira em relação ao clima, especialmente às variações estacionais, e é utilizado para interpretar como as culturas interagem com as diferentes regiões climáticas (LEÃO; PEREIRA, 2000).

Os poucos trabalhos existentes sobre fenologia da videira no Brasil representam referências valiosas, porém seus resultados não podem ser extrapolados de uma região para outra. Portanto, estudos sobre o comportamento de cultivares em cada região são necessários.

Autores como Baggiolini em 1952, Eichorn e Lorenz em 1977 descreveram alguns sistemas de classificação para os estádios fenológicos da videira (PEDRO JÚNIOR et al., 1989; MULLINS; BOUQUET; WILLIAMS, 1994). A introdução e a caracterização de cultivares têm sido objeto de muitos estudos, devido à importância de selecionar cultivares mais promissoras do ponto de vista agronômico e econômico para a substituição de cultivares tradicionais (SILVA; PEREIRA; MARTNS, 1990; CAMARGO; MASHIMA; CZERMAINSKI, 1997).

A fenologia varia em função do genótipo e das variações estacionais do clima de cada região produtora (LEÃO; SILVA, 2003). Ela também fornece informações ao viticultor das possíveis datas de colheita e subsídios do potencial climático destas regiões para o cultivo da uva (PEDRO JÚNIOR et al., 1993).

O conhecimento das relações entre o desenvolvimento da videira e as condições climáticas pode ser utilizado para: a melhoria do manejo das práticas agrícolas, a programação de colheita, a regionalização dos cultivos e a elaboração de modelos de início e duração de períodos fenológicos, além da previsão de produtividade e qualidade dos frutos de uma safra (BOLIANI; PEREIRA, 1996).

A espécie Vitis rotundifolia pertence ao subgênero Muscadinia, sendo muito resistente à maioria das pragas e doenças que atacam a videira, à exceção da podridão negra, é sensível ao óxido de cálcio e à carência de magnésio. Possui difícil hibridação com espécies da seção Euvitis, devido à diferença no número cromossômico. Possui cachos pequenos, bagas médias ou grandes, em geral de cor marrom escuro, às vezes de cor clara ou bronzeadas. Comercialmente cultivada nos Estados Unidos, em especial, na Flórida, Geórgia, Carolina do Norte e do Sul, é originária dos bosques úmidos do Sul dos Estados Unidos (QUEIROZ-VOLTAN; PIRES, 2003).

As informações sobre o comportamento fenológico da videira na região de Pinhais no Estado do Paraná são escassas, apesar de seu cultivo ser comum nos municípios vizinhos. A avaliação fenológica das cultivares de $V$. rotundifolia, será de fundamental importância para a melhor avaliação do potencial das cultivares para a região em questão, visando principalmente o manejo agroecológico. Desta forma o objetivo do presente trabalho foi caracterizar o ciclo fenológico de nove cultivares de Vitis rotundifolia na região de Pinhais-PR.

O estudo foi realizado na coleção de cultivares de V. rotundifolia, implantada em julho de 1999, no Setor de Fruticultura da Estação Experimental do Canguiri da Universidade Federal do Paraná 
(latitude $25^{\circ} 25^{\prime} \mathrm{S}$ e longitude $49^{\circ} 08^{\prime} \mathrm{W}$, altitude 930 m), município de Pinhais - PR.

Para o período de agosto de 2004 a abril de 2005, a temperatura média mensal, registrada pela estação meteorológica do SIMEPAR em Pinhais-PR foi de $14,4^{\circ} \mathrm{C}, 17,4^{\circ} \mathrm{C}, 16^{\circ} \mathrm{C}, 17,9^{\circ} \mathrm{C}, 18,9^{\circ} \mathrm{C}, 20^{\circ} \mathrm{C}, 20^{\circ} \mathrm{C}$, $20,1^{\circ} \mathrm{C}$ e $19^{\circ} \mathrm{C}$, respectivamente. A precipitação mensal para o mesmo período foi de $20,6 \mathrm{~mm}$, $53,6 \mathrm{~mm}, 169,8 \mathrm{~mm}, 90,6 \mathrm{~mm}, 153 \mathrm{~mm}, 141,8 \mathrm{~mm}$, $67,6 \mathrm{~mm}, 123,8 \mathrm{~mm}$ e $85,4 \mathrm{~mm}$ (SIMEPAR, 2009).

As plantas foram conduzidas em espaldeiras com três fios e espaçamento de $2 \mathrm{~m}$ entre plantas na linha. No ciclo avaliado as plantas não receberam poda, adubação ou tratamentos fitossanitários.

Foram realizadas observações fenológicas em duas plantas adultas de cada cultivar, em nove cultivares de $V$. rotundifolia, a saber: Topsail, Dixie, Roanoke e Magnólia (brancas) e Magoon, Creek, Regale, Bontiful e Noble (tintas). A escala de fenologia foi definida com base na classificação publicada por Eichorn e Lorenz em 1977 citados por Mullins, Bouquet e Williams (1994), cuja escala apresenta 47 fases durante todo o ciclo da videira, e Pedro Júnior et al. (1989), que definiram uma escala para 'Niagara Rosada' que possui 17 fases. Desta forma a escala utilizada possui os seguintes estádios fenológicos: 1) Gema dormente; 2) Gema inchada; 3) Gema algodão; 4) Ponta verde; 5) $1^{\text {a }}$ folha separada; 6) 2 a 3 folhas separadas; 7) 5 a 6 folhas separadas; 8) Inflorescência desenvolvida; 9) Botões florais separados; 10) 50\% das flores abertas; 11) Frutificação; 12) Grãos “chumbinho"; 13) Grãos “ervilha"; 14) Meia-baga; 15) Tamanho final; 16) Mudança de cor; 17) Maturação plena; 18) Término da colheita. Os estádios podem ser observados na (Figura 1). Para as cultivares brancas o estádio 16 não foi avaliado. O início das avaliações foi em agosto de 2004 e o término em abril de 2005.

De acordo com o padrão fenológico estabelecido, durante todo o ciclo desde o inchamento das gemas (Estádio 2) até o término da colheita (Estádio 18) ou início da queda das folhas, a cultivar Topsail foi a que apresentou o menor ciclo (214 dias) e a cultivar Magnólia (234 dias) o maior entre as uvas de cor branca (Figura 1), enquanto entre as uvas tintas, o menor ciclo foi observado na cultivar Magoon (222 dias) e o maior na cultivar Noble (234 dias) (Figura 2).

O início das brotações (Estádio 4 - Ponta verde) surgiu com maior precocidade entre as uvas de cor branca na cultivar Dixie aos 5 dias e as mais tardias foram a 'Magnolia' e a 'Roanoke' aos 9 dias; entre as uvas tintas na 'Creek' e na 'Noble' as brotações também surgiram 9 dias após a fase de gema inchada (Figuras 1 e 2). Por outro lado, quando se analisou desde a fase da gema algodão (Estádio 3) até a inflorescência desenvolvida (Estádio 8), constataram-se períodos desuniformes entre as nove cultivares de Vitis rotundifolia. Enquanto algumas cultivares apresentaram para este período até 81 dias como a 'Creek', 64 dias na 'Dixie' e 57 dias na 'Topsail', outras apresentaram períodos bastante curtos como a 'Regale' (25 dias), a 'Magnolia' e a 'Noble' (28 dias) e a 'Magoon' (29 dias), sendo esses últimos semelhantes aos obtidos por Roberto et al. (2004), que encontraram 25 dias para a videira 'Isabel' (Vitis labrusca) na região noroeste do Paraná, mas superiores aos encontrados por Boliani e Pereira (1996) para as cultivares Itália e Rubi na região de Jaboticabal em São Paulo. Leão et al. (2000), com a cultivar Ribol na região do Vale do Rio São Francisco, obtiveram 45 dias para esse período, sendo esta cultivar descrita como uma cultivar de ciclo tardio, o que indica forte influência do genótipo das cultivares, que apresentam diferentes ciclos, mesmo em condições ambientais semelhantes.

No período entre a inflorescência desenvolvida (Estádio 8) e grão "ervilha” (Estádio 13) observouse o ciclo mais longo (95 dias), para as cultivares Magnólia e Regale, e o ciclo mais curto para a cultivar Noble (53 dias), números esses superiores aos obtidos por Pedro Júnior et al. (2006) que obteve 16 dias, em um trabalho com a uva de mesa 'Niabell', sobre diferentes porta-enxertos. 

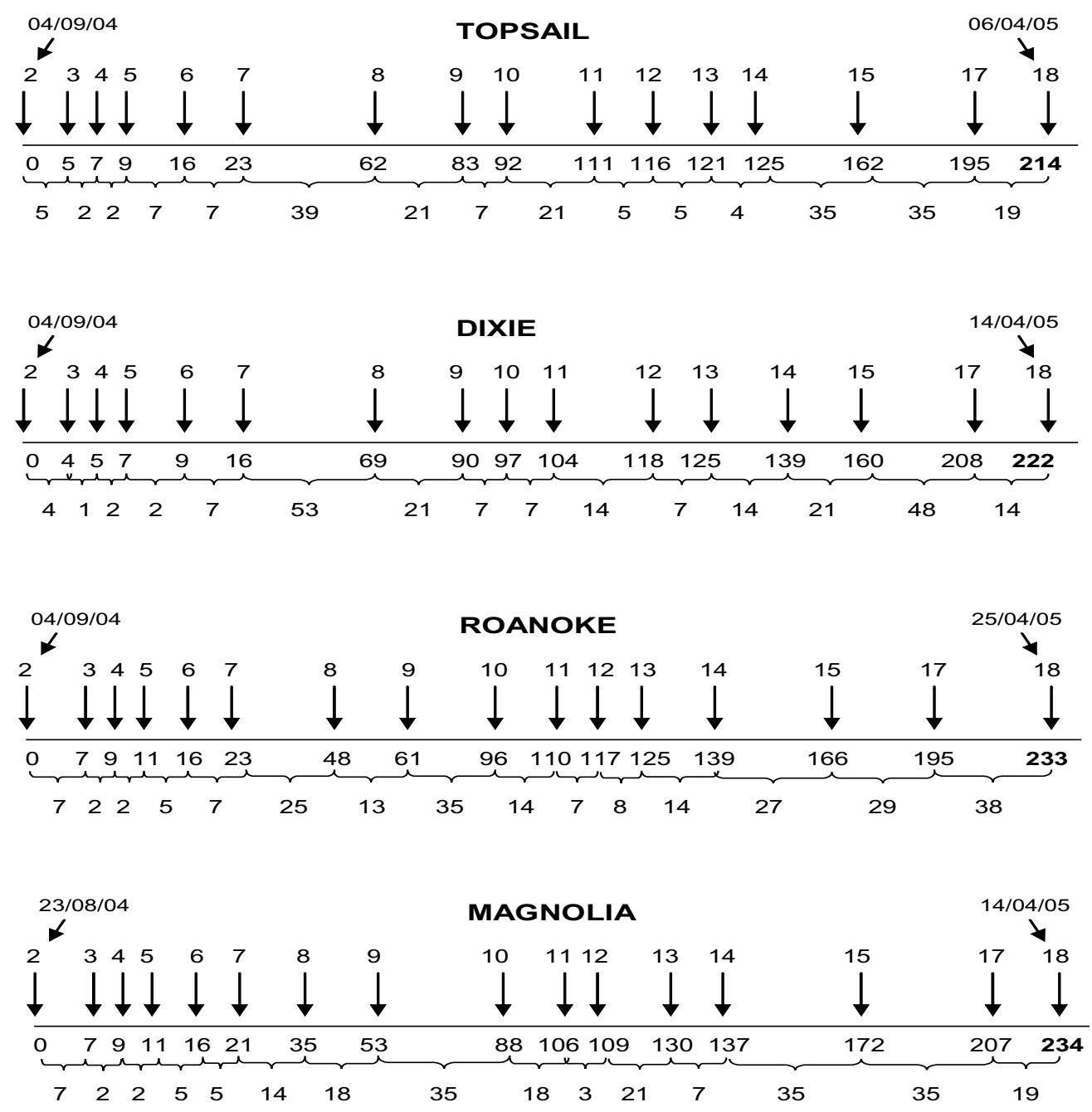

Figura 1. Fenologia das cultivares de uvas brancas de Vitis rotundifolia durante a safra 2004/2005. A primeira linha corresponde ao estádio fenológico, a segunda linha aos dias acumulados e a terceira linha a duração em dias de cada estádio. Pinhais-PR.

Estádios fenológicos: 1) Gema dormente; 2) Gema inchada; 3) Gema algodão; 4) Ponta verde; 5) 1ª folha separada; 6) 2 a 3 folhas separadas; 7) 5 a 6 folhas separadas; 8) Inflorescência desenvolvida; 9) Botões florais separados; 10) 50\% das flores abertas; 11) Frutificação; 12) Grãos "chumbinho"; 13) Grãos “ervilha"; 14) Meia-baga; 15) Tamanho final; 16) Mudança de cor; 17) Maturação plena; 18) Término da colheita. 

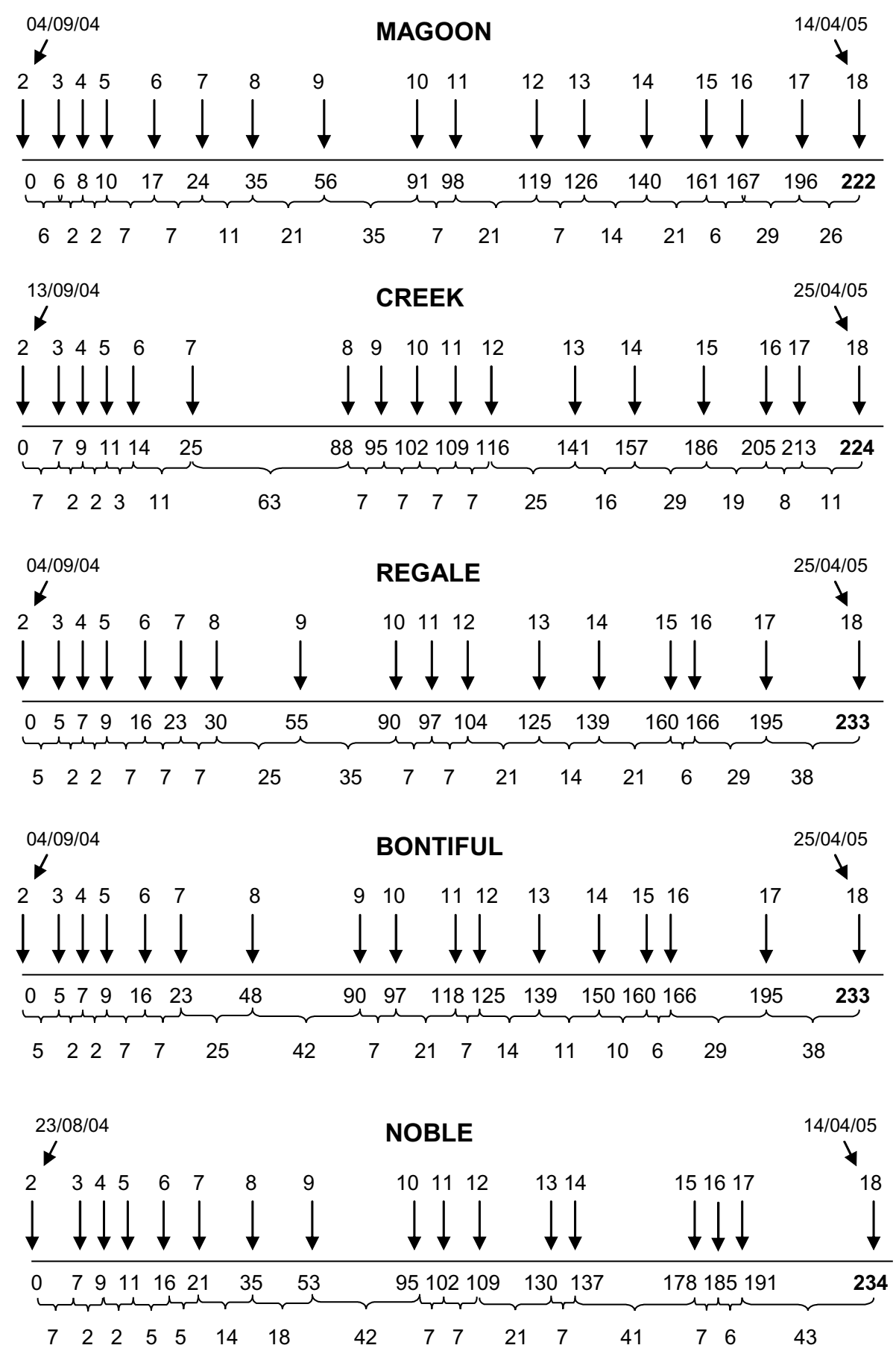

Figura 2. Fenologia de cultivares de uvas tintas de Vitis rotundifolia durante a safra 2004/2005. A primeira linha corresponde ao estádio fenológico, a segunda linha aos dias acumulados e a terceira linha a duração em dias de cada estádio. Pinhais-PR.

Estádios fenológicos: 1) Gema dormente; 2) Gema inchada; 3) Gema algodão; 4) Ponta verde; 5) 1'a folha separada; 6) 2 a 3 folhas separadas; 7) 5 a 6 folhas separadas; 8) Inflorescência desenvolvida; 9) Botões florais separados; 10) 50\% das flores abertas; 11) Frutificação; 12) Grãos "chumbinho"; 13) Grãos "ervilha"; 14) Meia-baga; 15) Tamanho final; 16) Mudança de cor; 17) Maturação plena; 18) Término da colheita. 
Quando se observa a fase do aparecimento da inflorescência (Inflorescência desenvolvida Estádio 8) à colheita (Estádio 18), percebe-se o longo ciclo da espécie Vitis rotundifolia, sendo que a cultivar Regale apresentou o período mais longo, de 203 dias, muito superiores aos obtidos em outros estudos. SATO (2007) pesquisou a fenologia e demanda térmica das videiras 'Isabel' e 'Rubea' sobre diferentes porta-enxertos e encontrou valores entre 88 e 124 dias para esse período acima; Roberto et al. (2004) conseguiram 93 dias para este período, na região de Maringá-PR com a videira 'Isabel' (Vitis labrusca); por Murakami et al. (2002), que obtiveram entre 116 e 136 dias com cultivar Itália (Vitis vinifera) sob diferentes épocas de poda e também por Silva et al. (2006) que conseguiram entre 130 e 160 dias, em um trabalho com a cultivar Patrícia também sob diferentes épocas de poda, entre o aparecimento da inflorescência e a colheita.

Vale destacar ainda, a desuniformidade de maturação entre os cachos da mesma planta e entre as bagas dentro do mesmo cacho e a elevada degrana que apresentou a espécie $V$. rotundifolia.

Conclui-se que: a) não há diferença do ciclo entre as cultivares de cores branca e tinta; $b$ ) as cultivares apresentam grande variação na duração da fase de gema algodão até a inflorescência desenvolvida, variando de 25 dias ('Regale') até 81 dias ('Creek'); c) o período entre o aparecimento da inflorescência e a colheita foi mais longo na cultivar Regale (203 dias) e mais curto na cultivar Creek (136 dias).

\section{Referências}

BOLIANI, A. C.; PEREIRA, F. M. Avaliação fenológica de videiras (Vitis vinifera L.), cultivares Itália e Rubi, submetidas à poda de renovação na região oeste do Estado de São Paulo. Revista Brasileira de Fruticultura, Cruz das Almas, v. 18, n. 2, p. 193-200, 1996.

CAMARGO, U.A.; MASHIMA, C. H.; CZERMAINSKI, A. B. C. Avaliação de cultivares de uvas apirênicas no Vale do São Francisco. Bento Gonçalves: EMBRAPACNPUV, 1997. 7 p. (Circular Técnica, 26).
INSTITUTO TECNOLÓGICO SIMEPAR. Temperatura média e precipitação mensal. Curitiba: SIMEPAR. 2009. (Arquivo Eletrônico Word for Windows).

LEÃO, P. C. S.; NACHTIGAL, J. C.; PEREIRA, F. M.; KOBA, W. Y. Comportamento fenológico e produtivo das variedades de uva 'Ribol`e 'Superior Seedless' na região de Jaboticabal, SP. Revista Brasileira de Fruticultura, Jaboticabal, v. 22, n. 2, p. 300-302, 2000.

LEÃO, P. C. S.; PEREIRA, F. M. Comportamento fenológico de seis variedades de uva sem sementes nas condições tropicais do vale do rio São Francisco. Revista Brasileira de Fruticultura, Jaboticabal, v. 22, n. 2, p. 170-175, 2000.

LEÃO, P. C. S.; SILVA, E. E. G. Caracterização fenológica e requerimentos térmicos de variedades de uvas sem sementes no vale do São Francisco. Revista Brasileira de Fruticultura, Jaboticabal, v. 25, n. 3, p. 458-460, 2003.

MULLINS, M. G.; BOUQUET, A.; WILLIAMS, L. E. Biology of the grapevine. Cambridge: University Press, 1994. $239 \mathrm{p}$.

MURAKAMI, K. R. N.; CARVALHO, A. J. C.; CEREJA, B. S.; BARROS, J. C. S. M.; MARINHO, C. S. Caracterização fenológica da videira cv. Itália (Vitis vinifera L.) sob diferentes épocas de poda na região norte do Estado do Rio de Janeiro. Revista Brasileira de Fruticultura, Jaboticabal, v. 24, n. 3, p. 615-617, 2002.

PEDRO JÚNIOR, M. J.; HERNANDES, J. L.; ABRAMIDES, P. L. G.; POMMER, C. V.; PEZZOPANE, J. R. M. Fenologia e produção da cultivar tetraplóide de uva de mesa Niabell sobre diferentes porta-enxertos. Bragantia, Campinas, v. 65, n. 1, p. 109-114, 2006.

PEDRO JÚNIOR, M. J.; RIBEIRO, I. J. A.; POMER, C. V.; MARTINS, F. P. Caracterização de estádios fenológicos da videira Niagara Rosada. In: CONGRESSO BRASILEIRO DE FRUTICULTURA, 10., 1989, Fortaleza. Anais... Fortaleza: SBF, 1989, p. 453-456. v. 1.

PEDRO JÚNIOR, M. J.; SENTELHAS, P. C.; POMMER, C. V.; MARTINS, F. P.; GALLO, P. B.; SANTOS, R. R.; BOVI, V.; SABINO, J. C. Caracterização fenológica da videira niagara rosada em diferentes regiões paulistas. Bragantia, Campinas, v. 52, n. 2, p. 153-160, 1993.

QUEIROZ-VOLTAN, R. B.; PIRES, E. J. P. A videira. In: POMMER, C. V. Uva: tecnologia de produção, póscolheita, mercado. Porto Alegre: Cinco Continentes, 2003. p. 37-61. 
ROBERTO, S. R.; SATO, A. J.; BRENNER, E. A.; SANTOS, C. E.; GENTA, W. Fenologia e soma térmica (graus-dia) para a videira 'Isabel' (Vitis labrusca) cultivada no Noroeste do Paraná. Semina: Ciências Agrárias, Londrina, v. 25, n. 4, p. 273-279, 2004.

SATO, A. J. Comportamento fenológico e produtivo das videiras 'Isabel' e 'Rubea' sobre diferentes portaenxertos no norte do Paraná. 62 p. Dissertação (Mestrado em Agronomia) - Departamento de Agronomia. Universidade Estadual de Londrina, Londrina, 2007.
SILVA, A. C.; PEREIRA, F. M.; MARTINS, F. P. Comportamento de cultivares americanas de videira na região de Jundiaí-SP. Científica, Jaboticabal, v. 18, n. 1, p. 61-70, 1990.

SILVA, R. P.; DANTAS, G. G.; NAVES, R. V.; CUNHA, M. G. Comportamento fenológico de videira, cultivar Patrícia em diferentes épocas de poda de frutificação em Goiás. Bragantia, Campinas, v. 65, n. 3, p. 399-406, 2006. 
